\title{
Gap edge attributes in Neotropical rainforest, Ecuador
}

\author{
Álvaro Cañadas López ${ }^{1,4}$, Diana Rade Loor ${ }^{2}$, Joffre Andrade Candell ${ }^{2}$, \\ José Ciro Hernández-Díaz ${ }^{3}$, Carlos Molina Hidrovo ${ }^{4}$, Marcos Zambrano Zambrano ${ }^{1}$ \\ \& Christian Wehenkel ${ }^{3 *}$ \\ 1. Universidad Laica Eloy Alfaro, ULEAM-Extensión Chone, Docente Investigador, Carrera Ingeniería Agropecuaria, \\ Av. Eloy Alfaro, Chone, Provincia de Manabí, Ecuador; alvarogustavo.canadaslopez@alumni.uni-goettingen.de, \\ marcos.zambrano@uleam.edu.ec \\ 2. Escuela Superior Politécnica Agropecuaria de Manabí. Docente Investigador del Centro de Investigación de las \\ Carreras de la ESPAM-MFL (CICEM), Calceta, Provincia de Manabí, Ecuador; yasbeth_rade15@hotmail.com, \\ joffrecan@hotmail.com \\ 3. Instituto de Silvilcultura e Industria de la Madera, Universidad Juárez del Estado de Durango, Boulevard Guadiana \\ \#501, Ciudad Universitaria, Torre de Investigación, C.P. 34120 Durango, Durango, México; jciroh@ujed.mx, \\ wehenkel@ujed.mex \\ 4. Instituto Nacional de Investigaciones Agropecuarias (INIAP), Estación Experimental Tropical Pichilingue, Programa \\ de Forestería, Km 5 vía Quevedo - El Empalme, cantón Mocache, Provincia Los Ríos, Ecuador; \\ carlos.molina@iniap.gob.ec \\ * Correspondence
}

Received 14-VI-2017. Corrected 18-X-2017. Accepted 17-XI-2017.

\begin{abstract}
The application of gap dynamics theory appears to be a promising option for tropical forest management and conservation. In the present study of a tree species-rich and old-growth Ecuadorian Neotropical forest, we assessed the spatial distribution of gaps and gap size in relation to: i) tree number at the gap edge, ii) number of tree species at the gap edge, iii) number of tree species per stem at the gap edge, iv) species similarity, v) species evenness at the gap edge, vi) size differentiation at the gap edge, vii) gap isolation and viii) species mingling at the gap edge. Our results demonstrated that the spatial distribution of gaps was random. Various gap attributes were strongly associated with gap size. The number of tree species per stem at the gap edge was negatively correlated to the gap size. Gap sizes up to $50 \mathrm{~m}^{2}$ were mostly sufficient to generate tree species-rich forest stands. Assuming that our results were representative for an old-growth neotropical rainforest in Ecuador, our study remarks the following management recommendations: 1) Rainforests have a very complex spatial and diversity structure and logging activities should preferably be omitted because of adverse effects. 2) If logging is inevitable, this should mimic a random choice of trees and tree species, to prevent special selection of tree dimension and species; and a random distribution of trees to be logged, to produce gaps smaller than $50 \mathrm{~m}^{2}$ and never larger than $400 \mathrm{~m}^{2}$. Additionally, we suggest cutting not more than $5 \%$ of the tree biomass per 10-20 years period, to preclude stronger alterations of ecosystem processes, and the reduction of existing dead wood from the ecosystem. Rev. Biol. Trop. 66(1): 149-163. Epub 2018 March 01.
\end{abstract}

Key words: Agglomerative approach, gap size, Gini evenness index, size differentiation, species mingling, Sørensen similarity index.

The Western Amazon forest, one of the world's last wilderness areas, supports an extraordinarily high level of species richness across taxa (Bass et al., 2010). However, the increasing levels of human impacts have led to the need to extend nature reserves and apply different types of management regimes, in order to preserve forest biodiversity and dynamics. Besides, forests not included within protection systems, must also be managed in different ways to produce timber and preserve biodiversity (Cañadas, 2005). 
Forest structure affects a range of other properties, including biodiversity and habitat functions, and thus the quality of ecosystem services (Gadow et al., 2012). In many parts of the world, forestry objectives have been shifting from focusing on maximum production, to a wider perspective that includes biodiversity preservation and ecosystem functioning (Gadow, 2003). To achieve these targets, managers are increasingly designing cutting regimes that imitate natural disturbances, with the aim of generating more naturally structured forests (Schliemann \& Bockheim, 2011).

In many old-growth forests, as ecosystems distinguished by old trees and related structural attributes, tree fall gaps caused by tree death constitute the dominant type of disturbance (Whitmore, 1989). In this context, the concepts of "forest gap" and "gap phase" were introduced by Watt (1947), who used these terms in relation to forest patches created by one or more canopy trees falling. The main causes of canopy gaps in a variety of ecosystems are wind throw, insect damage, disease, acidic deposition, drought and climate change. The application of gap dynamics theory appears to be a promising option for tropical forest management and conservation. However, attempts to manage tropical forest based on these concepts are scarce (Schliemann \& Bockheim, 2011).

According to Arriaga (1988), Brokaw and Busing (2000) and Dubé, Fortin, Canham and Marceau (2001), gaps increase light levels and modify local environmental conditions, are required for nearly all tree species to reach canopy status, generate habitats for specific species, become preferential sites of natural regeneration and subsequent growth, form important sites of entry of new genetic variants and new taxa, and may support the existence of some herbivores. Gaps not only help maintain the characteristic uneven-age nature of old-growth forests, but also influence nutrient cycling and preserve soil and plant species diversity (Brokaw \& Busing, 2000).

Gap size, age, and distribution are important variables for defining gap status and are strongly associated with gap processes. These variables and other gap characteristics can indicate the regeneration potential for different taxa. A high level of disturbance will result in many gaps or in large gaps. This will lead to a relatively high proportion of species depending on forests gaps (Poorter, Jans, Bongers, \& Van Rompaey, 1994). Gap size may be computed by different methods based on two and three dimensional projections of the canopy gap. Gap age can be measured by tree ring analysis, whorl counts and degree of decomposition. At the landscape level, gap processes can be investigated by use of long-term plots, aerial photography, GIS, and increment cores at random points and transects. The processes involved in gap making or infilling can be predicted by several fine and large scale models (Schliemann \& Bockheim, 2011).

Currently, various studies on forest gaps attributes are available, but little research has considered the characteristics at gap edges. Understanding natural gap processes is crucial for establishing new forestry practices trying to mimic natural processes of forest disturbance. In the present study, of an old-growth tree species-rich Ecuadorian Neotropical forest, we used multivariate analysis to assess the spatial distribution of gaps and gap size, in relation to tree (stem) number at the gap edge, number of tree species at the gap edge, number of tree species per stem at the gap edge, species similarity at the gap edge, species evenness at the gap edge, size differentiation at the gap edge, gap isolation, and species mingling at the gap edges.

\section{MATERIAL AND METHODS}

Site description: The study was conducted in the old-growth forest of the Ávila Viejo community, between October and December 2011. This forest is located in the Province of Orellana, Canton Loreto $\left(0^{\circ} 38^{\prime} 14\right.$ " N \& $89^{\circ} 59^{\prime} 6$ " W) and comprises a 3000 ha tract of old-growth Neotropical forest, in the Protected Forest Sumaco lowland, buffer zone of the National Park Sumaco Napo-Galeras, Ecuador, 
located at an elevation of $450 \mathrm{~m}$ above sea level. The yearly rainfall in the area follows a tri-modal pattern, totalling $4000 \mathrm{~mm}$.year ${ }^{-1}$. The mean annual temperature is $24{ }^{\circ} \mathrm{C}$. The soils, derived from volcanic ash, are alluvial black soils with fine sand, and an irregular distribution of organic material (Cañadas, 1983). No vertebrate studies were carried out, and field work permit was granted by the Ministerio del Ambiente, Ecuador (http://ambiente.gob.ec/).

Field sampling: A 1 ha plot of Neotropical rainforest (the most representative forest of Canton Loreto) was chosen for its flat representative topography. Species, DBH, and the X and $\mathrm{Y}$ coordinate for each tree with diameter at breast height $(\mathrm{DBH}) \geq 10 \mathrm{~cm}$ were measured. Tree botanical species samples were identified by the National Herbarium of Ecuador. The study 1 ha plot was square $(100 \times 100 \mathrm{~m})$. Every open area (without trees of DBH $\geq 10$ $\mathrm{cm})$ was considered to be a "gap" if the opening in the horizontal projection of the canopy over the ground exceeded a predefined minimum area of $9.76 \mathrm{~m}^{2}(3.12 \times 3.12 \mathrm{~m})$ following Brokaw (1982) (Fig. 1). General information on gap size, stem number $(N)$, and tree species $(S)$ at the gap edge, according with Muth and Bazzaz (2002) is given in Table 1.

Patterns of gap distribution: Using the agglomerative approach method (AAM) and the Grid2-Simulation program (Vilčko, 2003), two adjacent quadrats $(3.12 \times 3.12 \mathrm{~m})$, in a 32 x 32 quadrants grid, were combined into blocks of two quadrants, which were in turn successively combined, until a hierarchy of block sizes $(r)$ ranging from $2,4,8,16, \ldots, K$ quadrates was obtained (Fig. 1). The betweenblock sums of squares from the block counts in pairs of blocks of size $r$ that make up a block of size $2 r$ were then calculated. The AAM was introduced by Cressie (1993), who analysed contiguous quadrat data by nested analysis of variance. Considering that $A_{i}$ and $B_{i}$ denote the number of events in the $i$ th pair of blocks, each

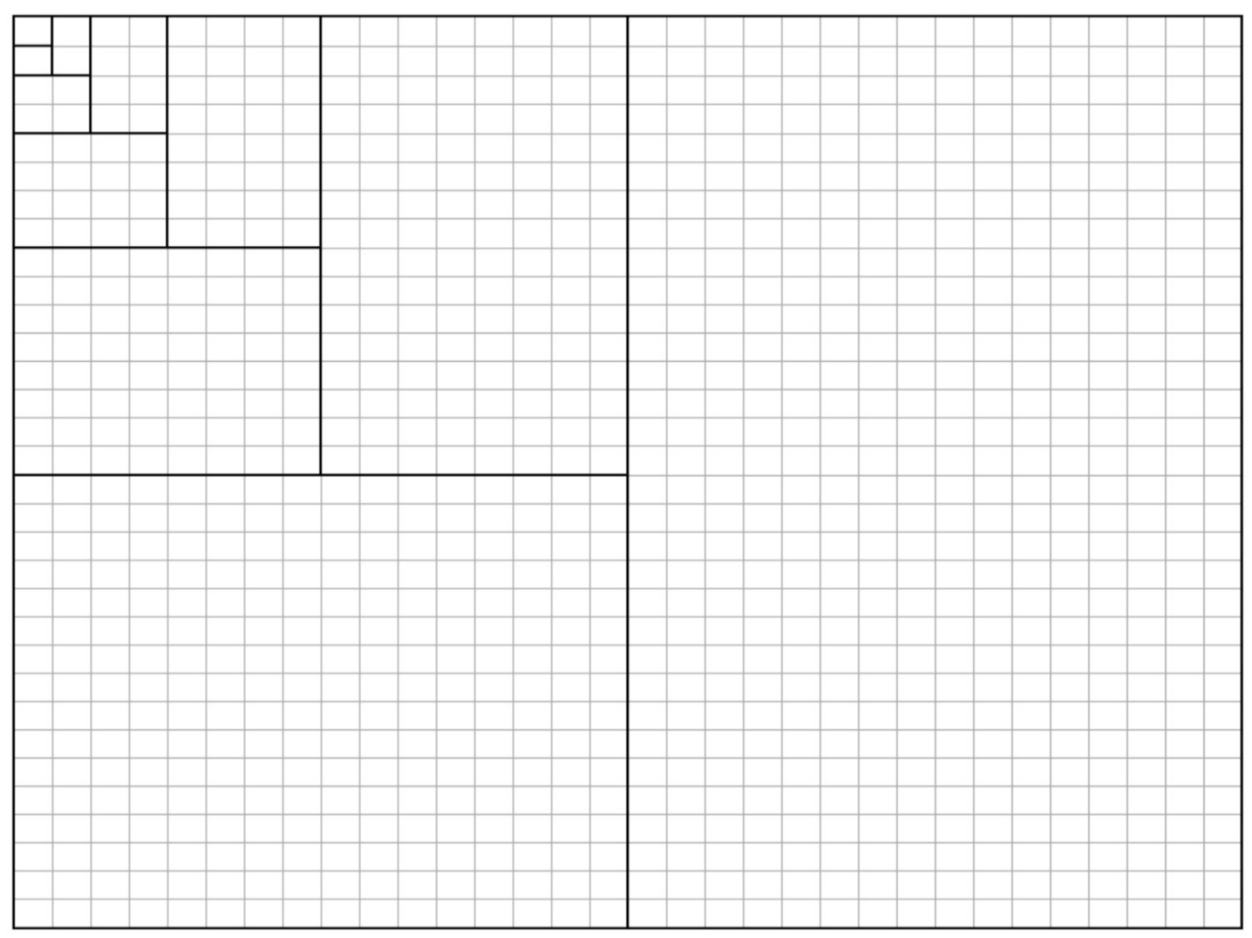

Fig. 1. Agglomeration approach method (AAM) for combining quadrats into blocks. 
TABLE 1

Gap size and numbers of species and stems at the gap edge of the one-hectare sampling plot of the tropical rainforest in the Ávila Viejo community, Canton Loreto.

\begin{tabular}{lccc} 
& Gap size $\left(\mathrm{m}^{2}\right)$ & Number of species & Number of stems \\
Minimum & 9.8 & 2.0 & 3.0 \\
Median & 54.1 & 5.6 & 10.4 \\
Maximum & 400.2 & 16.0 & 47.0 \\
Mean $( \pm \mathrm{SD})$ & $127.4( \pm 103.1)$ & $3.8( \pm 2.7)$ & $7.2( \pm 4.9)$ \\
\hline
\end{tabular}

containing $r$ quadrats, the between-blocks sum of squares for blocks $\left(S S_{r}\right)$ was then calculated (Cressie, 1993), as equations 1 and 2:

$$
\begin{gathered}
S S_{r}=\frac{1}{r} \sum_{i=1}^{m}\left(A_{i}^{2}+B_{i}^{2}\right)-\frac{1}{2 r} \sum_{i=1}^{m}\left(A_{i}+B_{i}\right)^{2} \\
S S_{r}=\frac{1}{2 r} \sum_{i=1}^{m}\left(A_{i}-B_{i}\right)^{2}
\end{gathered}
$$

Where: $r=$ block size in number of quadrants; $m=K / 2 r$, and the mean square is $M S r \equiv S S r / m$. Peaks in mean-squares are considered to be associated with a gap size.

Gap size and isolation: Gap edge and gap polygon were determined using ARC/ VIEW 3.2 software (Fig. 2). The gap size (GS) and average distance $\left(d_{i}\right)$ between the centre of each gap and other gaps centres provides a measure of gap isolation (I) (eq. 3), where $g$ equals the gap number from Rousseau and Van Hecke (1999).

$$
I=\frac{1}{g-1} \sum_{i=1}^{g-1} d_{i}
$$

Tree species number: The number of tree species at the edge $(S)$ of each gap was counted and the relationship between gap size and cumulative species number at the gap edges for all gaps surveyed was determined following Muth and Bazzaz (2002). The $S$ per individual tree number at the edges $(N)$ was also calculated to eliminate the area effect on species richness (Hubbell et al., 1999).

Species composition similarity: Species composition similarity at the edge was calculated with the Sørensen coefficient (eq. 4) (Weiner \& Solbrig, 1984):

$$
S ø r=2\left(\frac{S_{c}}{S_{a}+S_{b}}\right)
$$

Where Sør = Sørensen coefficient, $S_{c}=$ number of species present at both gap edges (habitats), $S_{a}, S_{b}=$ number of species present at gap edge $A$ and gap edge $B$, respectively.

Species evenness: Species evenness at the gap edge was calculated by means of the GINI evenness index $\left(G^{\prime}\right)$ (eq. 5) (Rousseau \& Van Hecke, 1999):

$$
G^{\prime}=1-\left(\frac{S+1}{S}-\frac{2}{S} \sum_{i=1}^{S}(S+1-i) p_{i}\right)
$$

Where $p_{i}$ equals the probability of occurrence of the $i$ th species, and $G^{\prime}=1$ for perfect evenness $\left(p_{1}=p_{2} \ldots=p_{s}\right)$. The relationship between the gap size and species richness at the gap edge was determined by using a species-gap size curve. The species richness was quantified using the number of species $(\mathrm{S})$ per each gap.

Size differentiation: According to Gadow et al. (2012), size differentiation $(U)$ at the gap edge is defined as the proportion of four neighbouring trees, which are smaller than a given reference tree. This is estimated with equation 6:

$$
U_{i}=\frac{1}{4} \sum_{j=1}^{4} v_{j}
$$

Where: $v_{j}=1$, if the neighbour is smaller than the reference tree $i$, and $v_{j}=0$ otherwise. If the reference tree has four neighbours, the index 


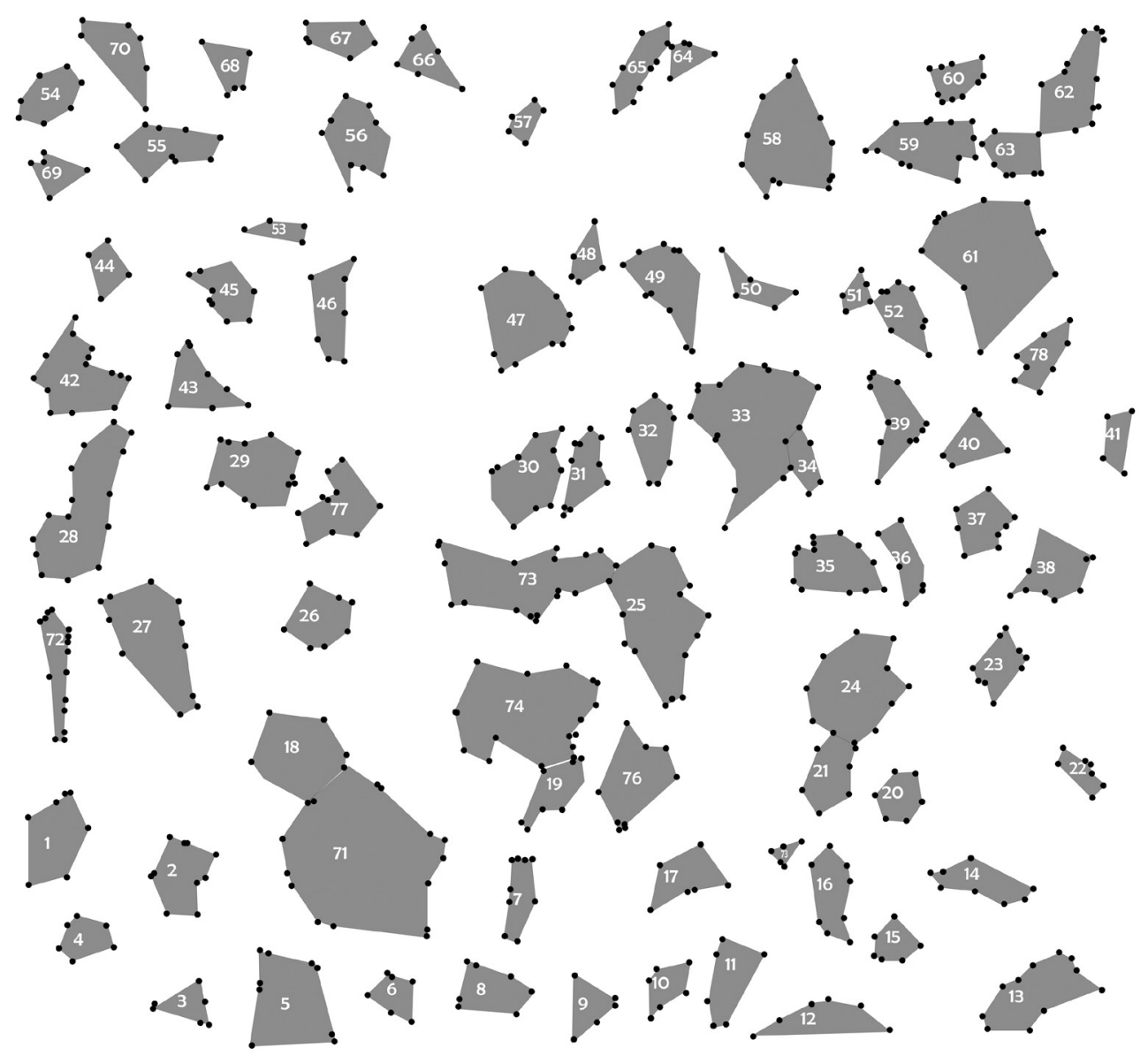

Fig. 2. Locations of the 78 selected gaps in the $100 \times 100 \mathrm{~m}$ (1 ha) plot.

$U_{\mathrm{i}}$ can have one of five values $(0,0.25,0.5$, 0.75 , and 1).

Species mingling: Species mingling at the gap edge and neighbourhood $\left(M_{i}\right)$ was defined as the proportion of trees of different species among the four neighbours of the reference tree (Gadow et al., 2012) (eq. 7):

$$
M_{i}=\frac{1}{4} \sum_{j=1}^{4} v_{j}
$$

with $v_{j}=\left\{\begin{array}{l}1, \text { neighbour } j \text { belongs to the same species } \\ \text { as reference tree } i \\ 0, \text { otherwise }\end{array}\right.$ and $0 \leq M_{i} \leq 1$
Given four neighbours, the mingling attribute $M_{i}$ can have one of five values $(0 ; 0.25$; $0.5 ; 0.75$ and 1$)$.

Principal Component Analysis (PCA): The variables tree number at the gap edge $(N)$, number of tree species at the gap edges $(S)$, number of tree species per stem at the gap edge $(S / N)$, species similarity at the gap edge $(S \varnothing r)$, gap size $(G S)$, species evenness at the gap edge $\left(G^{\prime}\right)$, size differentiation at the gap edge $(U)$, gap isolation $(I)$, and species mingling at the gap edge $(M)$, were analysed to detect any relationships between variables using Principal Component Analysis with varimax rotation, and the Spearman correlation index $\left(r_{s}\right)$, by using XLSTAT 2015.1.02 for Windows. The 
Bartlett test was applied to test the significance of eigenvalues.

Cluster analysis: Cluster analysis is a multivariate procedure that divides the sample into groups that are described by specific characteristics. The goal of this procedure is to form clusters of individuals that are almost homogenous but widely separated from other clusters by their heterogeneity.

In this study, i) the gap attributes $N, S$, $S / N, S ø r, G S, G^{\prime}, U, I$ and $M$, along with ii) the algorithms of $k$-means clustering besides the Calinski-Harabasz criterion and iii) the Affinity Propagation (AP) clustering (with the input preference to the $0,0.01$ and 0.5 quantiles $(q)$ of the input similarities) were used to analyse gap cluster structures. $k$-means is an iterative, data-partitioning algorithm and requires as input a matrix of points in different dimensions and a matrix of $K$ initial cluster centres in $J$ dimensions, using the Euclidean distance between points and clusters. The general procedure is to search for a $K$-partition with locally optimal within-cluster sum of squares by moving points from one cluster to another (Hartigan \& Wong, 1979).

In contrast with $k$-means, the AP is a relatively new clustering algorithm that detects exemplars among data points and forms groups of data points around these exemplars. It works by simultaneously considering all data point as potential exemplars and exchanging messages between data points until a set of exemplars and clusters is optimized. AP does not need to be given a pre-defined number of clusters (Frey \& Dueck, 2007). The Calinski-Harabasz criterion (sometimes called the variance ratio criterion (VRC)) and an AP search algorithm were used to determine the most suitable number of clusters. The VRC minimize the within-group sum of squares and maximize the betweengroup sum of squares. The highest VRC value corresponds to the optimal set of most compact clusters (Legendre \& Legendre, 2012).

Cluster analyses were performed using the R Script for $K$-Means Cluster Analysis and "apcluster" software packages (Bodenhofer,
Kothmeier, \& Hochreiter, 2011) implemented in the free statistical application R ( R Core Team, 2014).

\section{Canonical Discriminant Analysis} (CDA): Canonical Discriminant Analysis was then used to examine attribute differences between gap clusters detected by cluster analysis (calculated by AP with $q=0.01$ ). The Wilk's Lambda test was used to check the significance

TABLE 2

Tree families and genera found at the gap edges of the one-hectare plot of the tropical rainforest in the Ávila Viejo community, Canton Loreto, Amazonian Ecuador.

\begin{tabular}{|c|c|}
\hline Family & Genus \\
\hline Anacardiaceae & Spondias \\
\hline Anacardiaceae & Tapirira \\
\hline Annonaceae & Guatteria \\
\hline Arecaceae & Iriartea \\
\hline Araliaceae & Schefflera \\
\hline Bignoniaceae & Jacaranda \\
\hline Boraginaceae & Cordia \\
\hline Burseraceae & Dacryodes \\
\hline Burseraceae & Protium \\
\hline Cecropiaceae & Cecropia \\
\hline Cecropiaceae & Pourouma \\
\hline Clusiaceae & Rheedia \\
\hline Clusiaceae & Calophyllum \\
\hline Euphorbiaceae & Alchornea \\
\hline Euphorbiaceae & Hyeronima \\
\hline Fabaceae & Calliandra \\
\hline Fabaceae & Myroxylon \\
\hline Lauraceae & Ocotea \\
\hline Lauraceae & Nectandra \\
\hline Melastomataceae & Miconia \\
\hline Melastomataceae & Mouriri \\
\hline Meliaceae & Guarea \\
\hline Mimosoideae & Inga \\
\hline Moraceae & Ficus \\
\hline Moraceae & Batocarpus \\
\hline Moraceae & Perebea \\
\hline Myristicaceae & Otoba \\
\hline Myristicaceae & Virola \\
\hline Tiliaceae & Apeiba \\
\hline Rubiaceae & Warszewiczia \\
\hline Sapotaceae & Pouteria \\
\hline Sapotaceae & Chrysophyllum \\
\hline Violaceae & Leonia \\
\hline
\end{tabular}


of the clusters defined by AP with $q=0.01$, and the Bartlett test was used to test the significance of eigenvalues (Everitt \& Dueck, 2001; Polit, 1996). This analysis, including a cross validation was carried out with XLSTAT 2015.1.02 for Windows.

\section{RESULTS}

A total of 77 tree species and 811 individuals were recorded at the edges of 78 gaps (in a $32 \times 32$ quadrant-grid of $3.12 \times 3.12 \mathrm{~m}$ quadrats). These trees represented $68.7 \%$ of the total number of trees observed in the whole one-hectare studied plot. The total area occupied by all gaps was $4011 \mathrm{~m}^{2} / \mathrm{ha}$. The family and genus of each species represented by individuals in more than $20 \%$ of the gap edges are listed in Table 2. Overall, 1180 trees were recorded in the one-hectare plot.

The gaps were distributed in a completely spatially random manner in the research plot (Fig. 3). In none of the cases the peak mean square occurred in blocks sizes (full line). This result defines a complete spatial random distribution of the gaps in the research plot. The number of new species per unit of gap size remained below $10 \%$ for gap sizes above 127 $\mathrm{m}^{2}$ (Fig. 4). This point was considered to be a mean threshold differentiating between small and large gaps. Fifty-eight out of the 78 gaps (74 \%) were smaller than $50 \mathrm{~m}^{2}$. Most (70\%) of the tree species found in the whole plot were found at the gap edges.

The greater the species mingling in class 0 (see eq. 8), the more different tree species were intermingled. In total, $95 \%$ of the species at the gap edge were surrounded by either four or three neighbours belonging to different species (Fig. 5).

The distribution of size differentiation at the gap edge $(U)$ (Fig. 6) was skewed to the left, showing that $35 \%$ of the reference trees were dominant in their immediate vicinity, while most trees $(65 \%)$, were surrounded by at least three larger neighbours.

After a varimax rotation, the first three axes of the PCA explained $68.6 \%$ of the total variance (eigenvalues: $\lambda_{1}=3.64, \lambda_{2}=1.418$, $\left.\lambda_{3}=1.31\right)$. The Bartlett's test showed that the

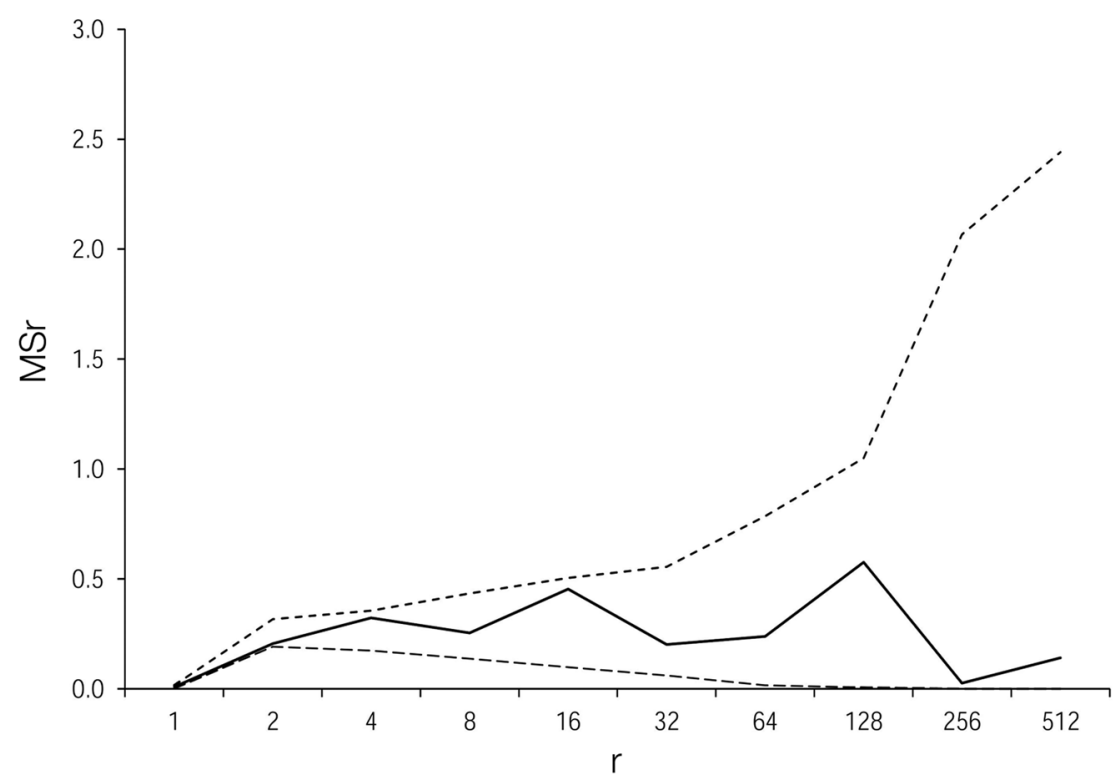

Fig. 3. Patterns of gap distribution established using the agglomerative approach method. Mean square MSr (solid line) versus block size r, together with $95 \%$ simulation envelopes (dashed lines) for the gaps in one-hectare sample plot. Ávila Viejo community, Canton Loreto. 


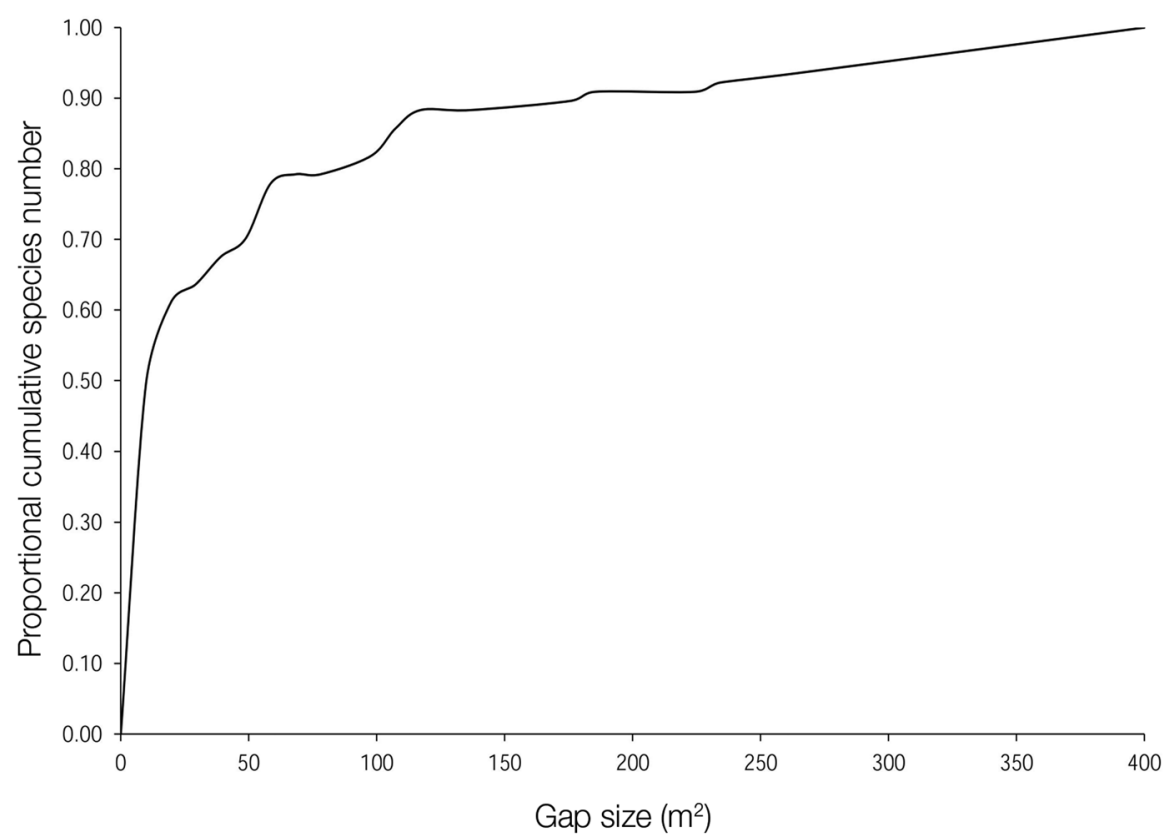

Fig. 4. Cumulative number of species at the gap edge-gap size curve for the 78 selected gaps surveyed in the one-hectare plot of tropical rain forest in the Ávila Viejo community, Canton Loreto.

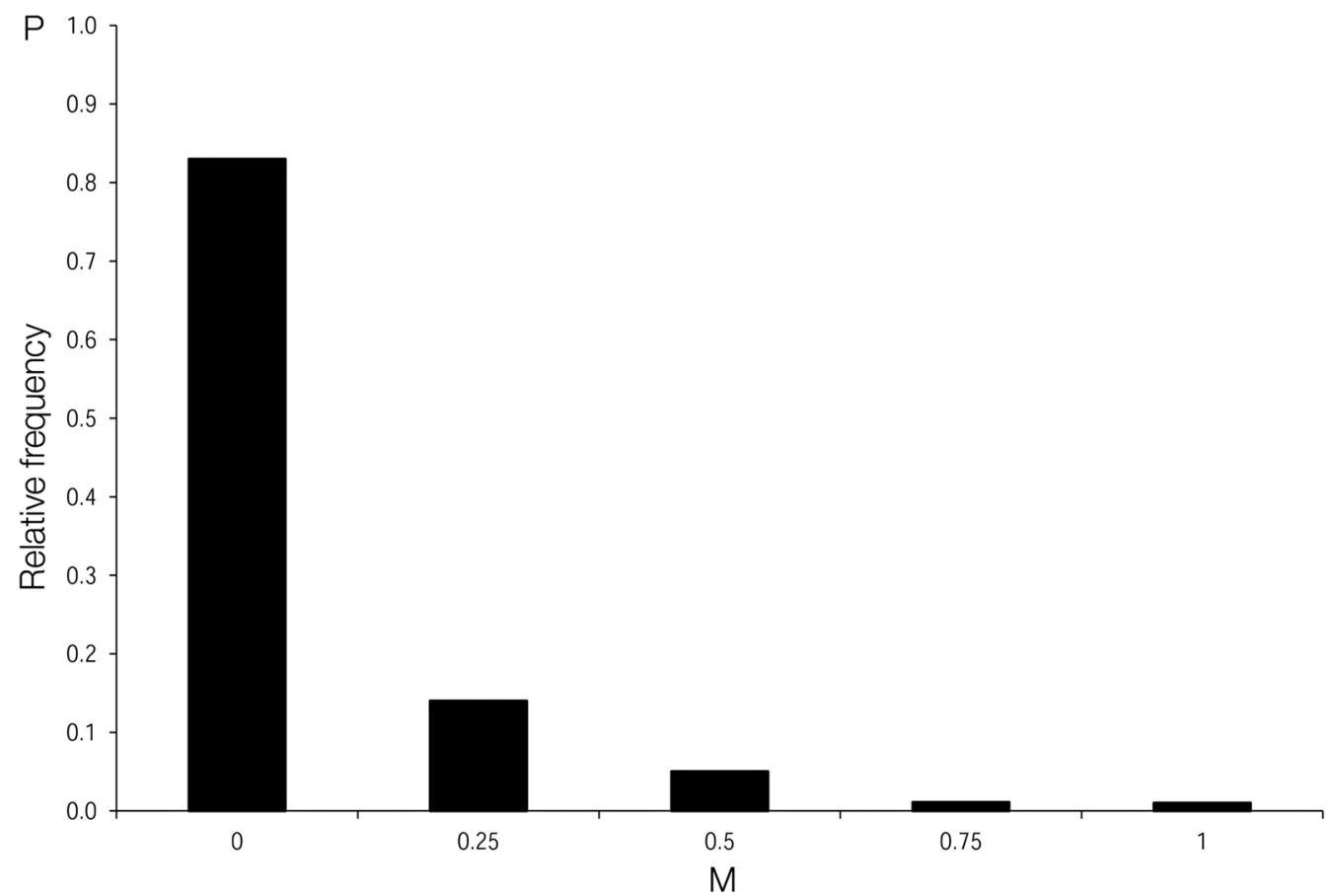

Fig. 5. Species mingling distribution (M) of the total gaps surveyed in the Ávila Viejo community, Canton Loreto. 


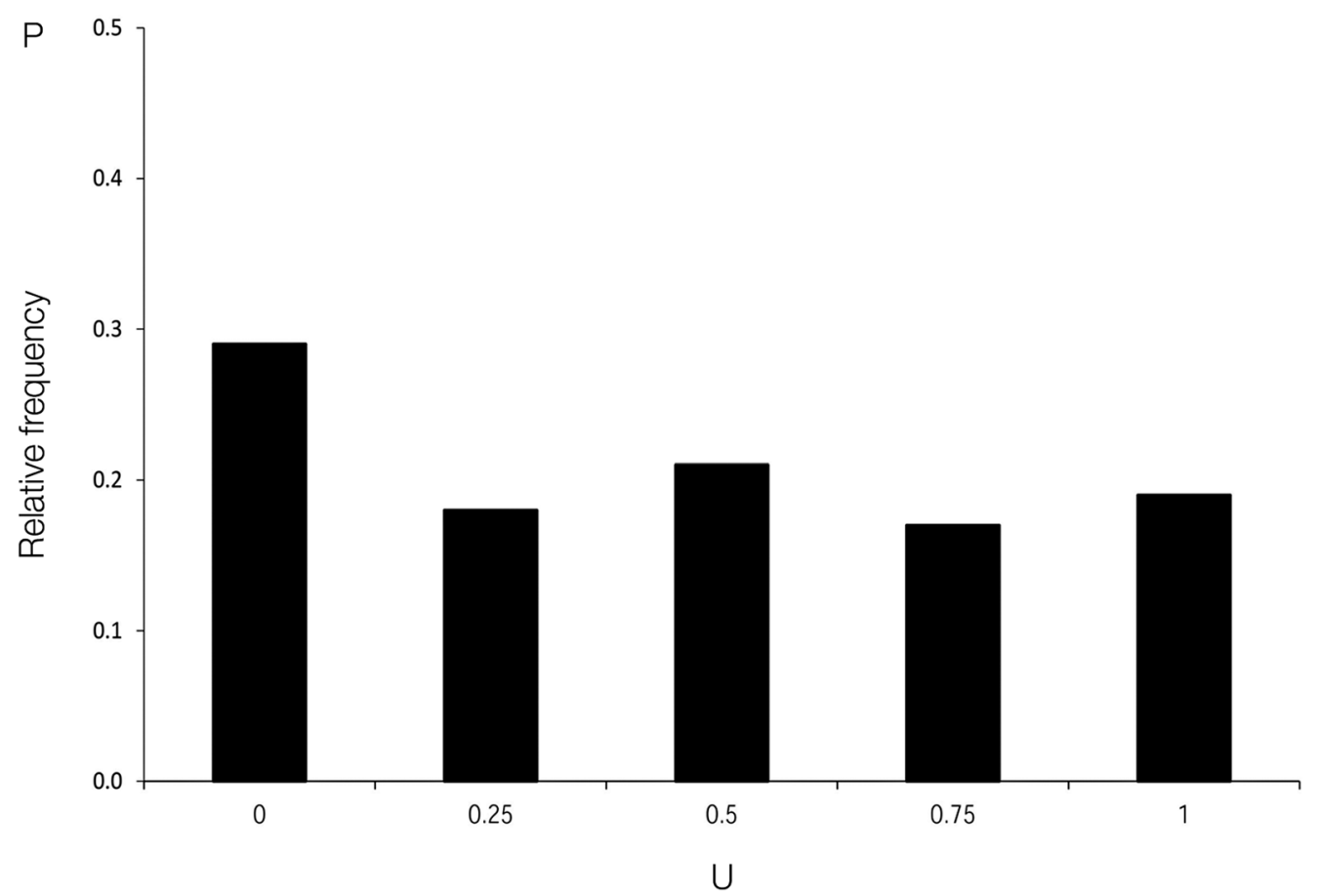

Fig. 6. Size differentiation distribution (U) of all gaps surveyed in the Ávila Viejo community, Canton Loreto.

eigenvalues of the first three principal components were statistically significantly different from each other $(\mathrm{P}<0.0001)$. Principal component 1 explained the variables number of tree species at the gap edge $(S)$ and total number of individuals at the gap edge $(N)$. The values of $N\left(r_{s}=0.62\right), M\left(r_{s}=0.68\right)$ and $G^{\prime}\left(r_{s}=0.73\right)$ increased $(\mathrm{P}<0.0001)$ with the size of the gaps $(G S)$. Species richness $(S)$ was strongly positively associated with $N\left(r_{s}=0.84, \mathrm{P}<0.0001\right)$, but not with GS. Principal component 2 elucidated $S / N$, gap size $(G S)$, species mingling index at the gap edge $(M)$, and species evenness at the gap edge $\left(\mathrm{G}^{\prime}\right)$. $S / N$ was negatively correlated with $G S\left(r_{s}=-0.59, \mathrm{P}<0.0001\right)$ and $M$ $\left(r_{s}=-0.46, \mathrm{P}<0.0001\right)$. Principal component 3 described about $14.5 \%$ of the total variability and defined distribution of tree size differentiation at the gap edge $(U)$ and species similarity at the gap edge (Sør). Gap isolation $(I)$ was not associated with other variables (Fig. 7).
After the cluster analysis, the CalinskiHarabasz criterion recommended two clusters as optimal number. The first group comprised the smallest 69 gaps $(88 \%)$ and the second group the 9 largest gaps (12\%). The Affinity Propagation (AP) clustering with $q=0$ also suggested the same two clusters. Then, AP with $q=0.01$ recommended three clusters and with $q=0.5$ thirteen groups.

Subsequently a cross validation, the Canonical Discriminant Analysis (Table 3, Fig. 8) of the three gap clusters (calculated by AP with $q=0.01$ ) revealed that on average 94.9 $\%$ of all gaps were correctly classified. The Bartlett's test indicated that the eigenvalues of the first two canonical functions were statistically significantly different from each other (P $<0.0001)$. The Wilk's Lambda indicated highly significant differences $(\mathrm{P}<0.0001)$ between these three gap clusters. From the first to the third gap cluster, the mean values of gap attributes $G S, N, M$ and $S$ increased monotonically 


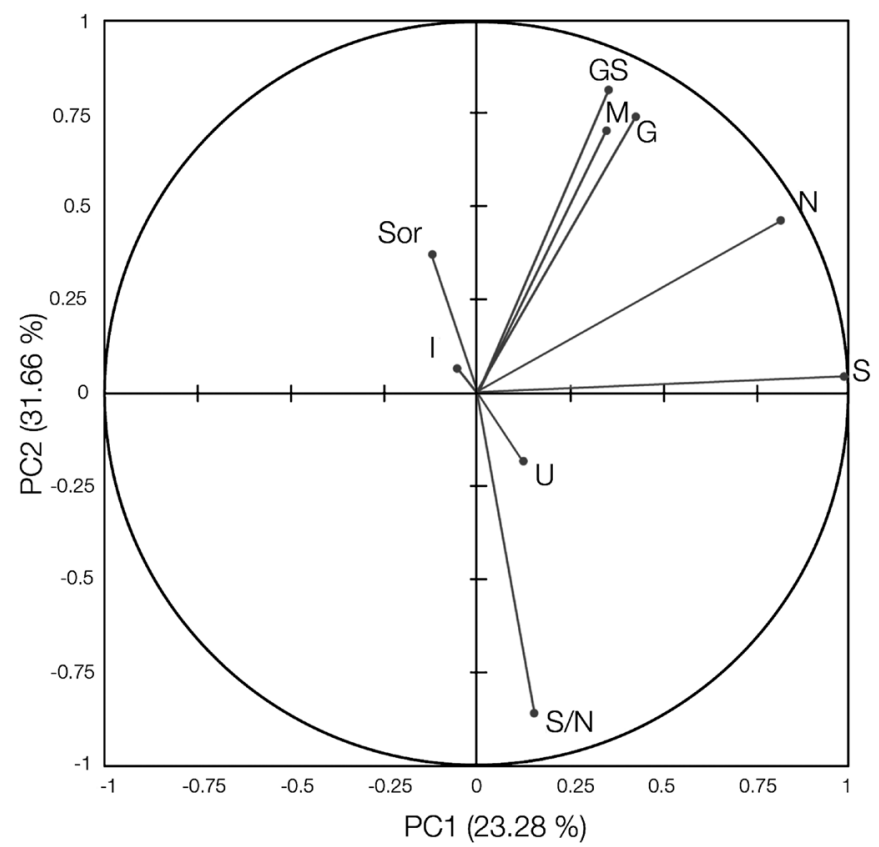

Fig. 7. Principal component analysis after varimax rotation for the 78 gaps surveyed in the Ávila Viejo community, Canton Loreto. The component loadings in the two axes (PC1 and PC2) of the centred standardized PCA are shown; GS = gap gize, $\mathrm{N}=$ individual number at the gap edge, $\mathrm{M}=$ mingling index at the gap edge, $\mathrm{I}=$ gap isolation, $\mathrm{S} / \mathrm{N}=$ number of tree species per stem at the gap edge, $\mathrm{G}^{\prime}=$ species evenness at the gap edge, and $\mathrm{S}=$ number of tree species at the gap edge.

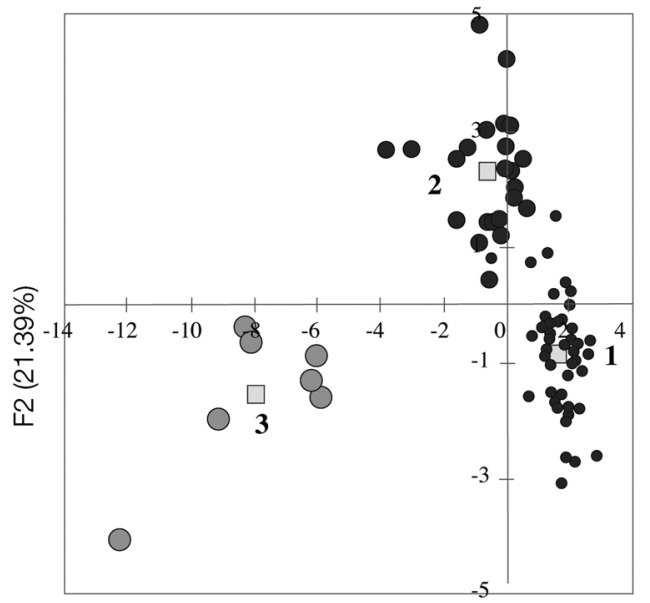

F1 (78.61\%)

Fig. 8. Relationship between three clusters of gaps separated by the Affinity Propagation (AP) clustering with the quantile $=0.01$ within a system of two first functions F1 and F2 for the gap community, Ávila Viejo community, Canton Loreto. The squares represent cluster centroids and circles represent gap observations. $1=$ the first cluster characterized by the smallest gap sizes, $2=$ the second cluster distinguished by the medium gap sizes, and $3=$ the third cluster characterized by the largest gap sizes. (mean GS from 20 to $232 \mathrm{~m}^{2}$, mean $N$ from six to 29 , mean $M$ from 0.16 to 0.47 and mean $S$ from four to eight), but the mean value of $S / N$ decreased from 0.68 to 0.29 (Fig. 8). The mean value of the gap isolation $(I)$ was highest in the second cluster (7.5) and lowest in the third cluster (3.8). The mean species evenness at gap edge also was highest in the second cluster (0.95), but lowest in the first cluster (0.87). The distribution of tree size differentiation at the gap edge $(U)$ and species similarity at the gap edge $(S ø r)$ varied very little among the three clusters.

\section{DISCUSSION}

The plot that we studied had a density of 1180 trees/ha. This resulted a similar value to the average of 1387 trees/ha reported by Unger, Homeier and Leuschner (2012), for which they evaluated 80 tropical forest plots (0.04 ha) of lowland and lower montane 
TABLE 3

Variability explained by canonical functions for the seven most important variables $(p<0.0001)$, that separated three gap clusters detected by the Affinity Propagation (AP) clustering with the quantile $=0.01$ within the total canonical structure, in the one-hectare plot of tropical rainforest in Ávila Viejo community, Canton Loreto

\begin{tabular}{lcc} 
& Canonical functions & F1 \\
Eigenvalue & 8.58 & 2.34 \\
Canonical correlation & 0.95 & 0.84 \\
Explained variance & $78.61 \%$ & $21.34 \%$ \\
Variables & & \\
Gap size $(G S)$ & -0.949 & \\
Individual number at the gap edge $(N)$ & -0.921 & \\
Mingling index at the gap edge $(M)$ & -0.794 \\
Gap isolation $(I)$ & 0.694 & \\
Number of tree species per stem at the gap edge $(S / N)$ & 0.556 & \\
Species evenness at the gap edge $(G)$ & & 0.627 \\
Number of tree species at the gap edge $(S)$ & & 0.501 \\
\hline
\end{tabular}

elevations of Amazonian Ecuador (across different edaphic and elevation gradients), close to our research plot, for which they inventoried all trees $\geq 10 \mathrm{~cm} \mathrm{DBH}$.

The spatial gap structure in the research plot in the Ávila Viejo community was randomly distributed. However, spatial analysis conducted in the moist forest of Tal National Park in South-West Ivory Coast, West Africa, showed that the occurrence of gaps is often not random, with some sites more likely to have gaps than others places (Poorter et al., 1994). Other studies also suggested that canopy gaps in old-growth Neotropical lowland forests are not spatially randomly distributed, but rather clustered around specific sites such as those with shallow soils (Van der Meer \& Bongers, 1996).

The cumulative species-gap size curve showed that $90 \%$ of all species at gap edges were found at the border of the most common group of "small" gaps $\left(\leq 127 \mathrm{~m}^{2}\right)$. These results were similar to those obtained in a study of sapling diversity in an Ecuadorian rainforest, where a threshold of $150 \mathrm{~m}^{2}$ was found between small and large gaps. This threshold is an important attribute of the gap distribution (Salvador-Van Eysenrode, Bogaert, Zak-Mnacek, \& Ceulemans, 2003). If tree species diversity at gap edges is the main factor influencing tree species diversity in gap regeneration, then the future regeneration in small gaps should also be species-rich. However, in the above-mentioned sapling study, only $30 \%$ of the tree species richness was observed in gaps up to $50 \mathrm{~m}^{2}$ (Salvador-Van Eysenrode et al., 2003). In another study, a sapling species richness of only $21 \%$ was found in gaps smaller than $50 \mathrm{~m}^{2}$ (Hubbell et al., 1999). In these studies, the main causes of species diversity in gap regeneration probably were: i) less adult tree species at the gap edge of small gaps, or/and, ii) an early high degree of speciesselective self-thinning, due to intra and interspecific competition-induced mortality in small gaps, during the course of population development in tree community (Lepš \& Kindlmann, 1987; Getzin, Wiegand, Wiegand, \& He, 2008; García-Domingo \& Saldana, 2013; Wehenkel, Brazão-Protázio, Carillo-Parra, MartínezGuerrero, \& Crecente-Campo, 2015), because of different seed production rate, dispersal, and vigour and shade tolerance of seedlings and saplings of different tree species (Canham, 1989). In contrast, the competition-induced mortality in the larger gaps was probably lower due to lower over story competition on understory gap regeneration.

The low value of the mingling index at the edge of different gaps showed substantial 
levels of local diversity. The tree species were almost always randomly mixed at the gap border in this one-hectare sample plot, because each tree species was present in a proportion of about $3 \%$ on average. The nearest neighbours were therefore very likely to be of another tree species. This indicates similar capacity among the tree species found to tolerate the abiotic conditions, mainly shade (Kukkonen, Rita, Hohnwald, \& Nygren, 2008), and a low potential for competitive niche differentiation in this forest.

The distribution of tree size differentiation was different at the gap edge $(U)$, where most trees were surrounded by at least, three larger neighbours. This type of random distribution can be observed in uneven-aged and mixed forests with a reverse $J$-shaped DBH distribution and extremely small minimum balanced structure areas (BSA) and very low minimum balanced structure tree numbers (BSN) (Wehenkel, Corral-Rivas, Hernández-Díaz, \& von Gadow, 2011).

The results demonstrated that gap sizes up to $50 \mathrm{~m}^{2}$ were mostly sufficient to generate tree species-rich forest stands. In a previous study, gaps were found to vary in size between 20 and $705 \mathrm{~m}^{2}$ in a tropical rainforest in Panama (Brokaw, 1985). In other large studies, $70 \%$ of gaps were smaller than $50 \mathrm{~m}^{2}$, and only $0.7 \%$ of all the 1284 studied gaps were equal or larger than $400 \mathrm{~m}^{2}$ in a tropical forest (Panama) (Hubbell et al., 1999), while only $4 \%$ of the gaps exceeded $500 \mathrm{~m}^{2}$ in a rainforest in Costa Rica (Sanford, Braker, \& Hartshorn, 1986). Another study of 250000 trees in Panama demonstrated that only $5 \%$ of these trees were adapted to treefall gaps (Welden, Hewett, Hubbell, \& Foster, 1991). In contrast, in our study, the gaps were no larger than $400 \mathrm{~m}^{2}$ in the one-hectare sample plot. Therefore, if the aim of forest management is to keep the current species composition and biodiversity, logging gaps should preferably be no larger than 400 $\mathrm{m}^{2}$. This corresponds to a selective logging of maximum two neighbour large trees at a time. A mean gap size of $181 \mathrm{~m}^{2}$ by conventional selective logging of one single tree and $355 \mathrm{~m}^{2}$ by the logging of two neighbouring trees was reported for a tropical rainforest in Guyana (Dam, 2001). Besides, the authors of the same study also showed that nutrient availability is strongly associated with gap size (Dam, 2001).

The PCA analysis confirmed that the lack of correlation between gap size and isolation might be stochastic (see also Salvador-Van Eysenrode et al., 2003). The dense gap grid of 78 mostly small gaps per hectare may provide optimal conditions for regeneration of shadetolerant tree species, for which dispersal is limited due to large seed size (Canham, 1989).

In this study, relationships between other important characteristics of forest gaps were also observed. Tree species evenness, species and tree number at the edges of larger gaps were highest, probably due to a simple area effect (Hubbell et al., 1999). However, the number of tree species per stem at the edges $(S / N)$ of the largest gaps was significantly lower than that at the smaller gaps. Thus, the number of tree species per stem could control the gap size and influence resistance and resilience of the spatial tree structure in the plot (Gregorius, 2001; Kennedy et al., 2002).

Different tree species often have different life spans and sizes. Therefore, the probability that two or more trees of different species fall at the same time and create a gap is lower than for trees of the same species. Furthermore, the edges of small gaps probably provide more potential regeneration diversity or/and more niches than edges of large gaps, because of the better distribution of shadow and light. Therefore, niche differentiation in response to small changes in understory light may be an important factor in preserving intra habitat diversity (Svenning, 2000). Our finding contrasted with the non-significant to positive relationship between gap size and tree species number per stem, reported in another study (Hubbell et al., 1999). Forest gaps generally promote larger species richness, although usually by sustaining higher stem densities and not by providing more niches (Brokaw \& Busing, 2000).

Natural disturbances that create gaps in the canopy are important for stability, heterogeneity 
(species diversity), turnover rate, and spatial structure in Neotropical forests (Cañadas, 2005). Information about the characteristics of such gaps is therefore crucial for understanding the ecological performance of a forest. Such information can also be used to establish sustainable forest management systems (Wehenkel, Corral-Rivas, \& Gadow, 2014). Assuming that our results were representative for an old-growth neotropical rainforest in Ecuador, our study has allowed us to remark the following management recommendations: 1) This rainforest type has a very complex spatial and diversity structure; therefore, logging activities should preferably be omitted, since they will adversely affect these structures. 2) If logging is inevitable, then this intervention should mimic the structures found in this study, i.e., i) a random choice of tree species and sizes to be harvested, avoiding special selection of tree dimension and species, ii) a random distribution of trees to be logged, producing gaps commonly smaller than $50 \mathrm{~m}^{2}$ and never larger than $400 \mathrm{~m}^{2}$. Furthermore, we suggest cutting not more than $5 \%$ of the tree biomass in each period of 10-20 years, to preclude stronger alterations of ecosystem processes, and the reduction of existing dead wood into the ecosystem.

\section{RESUMEN}

Atributos de los bordes de los fragmentos en un bosque húmedo neotropical, en Ecuador. Aplicar la teoría de la dinámica de parches parece ser una opción prometedora para el manejo y conservación de los bosques tropicales. En el presente estudio se analizó la distribución espacial y el tamaño de los parches en relación con: i) el número de árboles en el borde del parche, ii) el número de especies arbóreas en el parche iii) número de especies arbóreas por tronco en el borde del parche, iv) similitud de las especies, v) uniformidad de las especies en el borde del parche, vi) separación del tamaño en el borde del parche, vii) aislamiento del parche y viii) borde del parche. Nuestros resultados demostraron que la distribución espacial de los parches fue aleatoria. Varios atributos de la vegetación se asociaron fuertemente con el tamaño del parche. El número de especies de árboles por fuste en el borde del parche se correlacionó negativamente con el tamaño del parche. Asumiendo que, nuestros resultados fueron representativos de un bosque neotropical en el Ecuador, nuestro estudio respalda las siguientes recomendaciones: 1) Este tipo de bosque húmedo tiene una diversidad espacial y estructural muy compleja; por lo tanto, las actividades de explotación forestal deberían omitirse, ya que afectarán negativamente sus estructuras. 2) Si la tala es inevitable, entonces deberían imitarse las estructuras naturales descritas en este estudio. Es decir, i) una selección aleatoria de especies de árboles a cosechar, con el fin de evitar la selección específica por dimensiones del arbolado o por especies, ii) en la distribución aleatoria de árboles debe tomarse en cuenta que los parches sean menores a $50 \mathrm{~m}^{2}$ y jamás mayores a $400 \mathrm{~m}^{2}$. Adicionalmente, se recomienda no cortar más del $5 \%$ de la biomasa arbórea en cada período de corta de entre 10 a 20 años, para evitar alteraciones mayores en los procesos del ecosistema y la reducción de madera muerta existente en estos ecosistemas.

Palabras clave: Diferenciación por tamaño; enfoque aglomerado; índice de uniformidad de Gini; índice de similitud de Sørensen; mezcla de especies.

\section{REFERENCES}

Arriaga, L. (1988). Gap dynamics of a tropical cloud forest in northeastern Mexico. Biotropica, 20(3), 178-184.

Bass, M. S., Finer, M., Jenkins, C. N., Kreft, H., CisnerosHeredia, D. F., McCracken, S. F., ... Di Fiore, A. (2010). Global conservation significance of Ecuador's Yasuní National Park. PloS One, 5(1), e8767.

Bodenhofer, U., Kothmeier, A., \& Hochreiter, S. (2011). APCluster: an $\mathrm{R}$ package for affinity propagation clustering. Bioinformatics, 27(17), 2463-2464.

Brokaw, N. V. (1982). The definition of treefall gap and its effect on measures of forest dynamics. Biotropica, 14(2), 158-160.

Brokaw, N. V. (1985). Gap-phase regeneration in a tropical forest. Ecology, 66(3), 682-687.

Brokaw, N., \& Busing, R. T. (2000). Niche versus chance and tree diversity in forest gaps. Trends in Ecology \& Evolution, 15(5), 183-188.

Canham, C. D. (1989). Different Responses to Gaps among Shade-Tollerant Tree Species. Ecology, $70(3), 548-550$.

Cañadas, L. (1983). El mapa bioclimático y ecológico del Ecuador. Ltda., Quito-Ecuador: Editores Asociados Cía.

Cañadas, Á. (2005). Providing information about natural resources as a base to support the decentralization of the forest sector in Canton Loreto-Ecuador. Göttingen, Germany: Forschungszentrum Waldökosysteme. 
Cressie, N. A. C. (1993). Statistics for Spatial Data, Revised Edition. Hoboken, NJ, USA: John Wiley \& Sons, Inc.

Dam, O. V. (2001). Forest filled with gaps: effects of gap size on water and nutrient cycling in tropical rain forest: a study in Guyana (Doctoral dissertation). Utrecht University Repository.

Dubé, P., Fortin, M. J., Canham, C. D., \& Marceau, D. J. (2001). Quantifying gap dynamics at the patch mosaic level using a spatially-explicit model of a northern hardwood forest ecosystem. Ecological Modelling, 142(1), 39-60.

Everitt, B. S., \& Dunn, G. (2001). Applied multivariate data analysis. London, Arnold: Oxford University Press.

Frey, B. J., \& Dueck, D. (2007). Clustering by passing messages between data points. Science, 315(5814), 972-976.

Gadow, Kv. (2003). Waldstruktur und Wachstum. Beilage zur Vorlesung. Göttingen, Germany: Uni. Göttingen.

Gadow, K. V., Zhang, C. Y., Wehenkel, C., Pommerening, A., Corral-Rivas, J., Korol, M., ... Zhao, X. H. (2012). Forest structure and diversity. In T. Pukkala \& K. V. Gadow (Eds.), Continuous cover forestry (pp. 29-83). Netherlands: Springer.

García-Domingo, J. L., \& Saldana, J. (2013). A pairapproximation model for spatial patterns in tree populations with asymmetrical resource competition. Mathematical Population Studies, 20(4), 175-191.

Getzin, S., Wiegand, T., Wiegand, K., \& He, F. (2008). Heterogeneity influences spatial patterns and demographics in forest stands. Journal of Ecology, 96(4), 807-820.

Gregorius, H. R. (2001). The notion of stability in open dynamical systems from an ecological perspective. International Journal of General System, 30(3), 347-378.

Hartigan, J. A., \& Wong, M. A. (1979). Algorithm AS 136: A k-means clustering algorithm. Journal of the Royal Statistical Society. Series C (Applied Statistics), 28(1), 100-108.

Hubbell, S. P., Foster, R. B., O’Brien, S. T., Harms, K. E., Condit, R., Wechsler, B., \& De Lao, S. L. (1999). Light-gap disturbances, recruitment limitation, and tree diversity in a neotropical forest. Science, 283(5401), 554-557.

Kennedy, T. A., Naeem, S., Howe, K. M., Knops, J. M., Tilman, D., \& Reich, P. (2002). Biodiversity as a barrier to ecological invasion. Nature, 417(6889), 636-638.

Kukkonen, M., Rita, H., Hohnwald, S., \& Nygren, A. (2008). Treefall gaps of certified, conventionally managed and natural forests as regeneration sites for
Neotropical timber trees in northern Honduras. Forest Ecology and Management, 255(7), 2163-2176.

Legendre, P., \& Legendre, L. (2012). Numerical ecology. Developments in environmental modelling (3th edition). Amsterdam: Elsevier Science Ltd.

Lepš, J., \& Kindlmann, P. (1987). Models of the development of spatial pattern of an even-aged plant population over time. Ecological Modelling, 39(1), 45-57.

Muth, C. C., \& Bazzaz, F. A. (2002). Tree canopy displacement at forest gap edges. Canadian Journal of Forest Research, 32(2), 247-254.

Polit, D. F. (1996). Data analysis \& statistics for nursing research. New York: Appleton \& Lange.

Poorter, L., Jans, L., Bongers, F., \& Van Rompaey, R. S. (1994). Spatial distribution of gaps along three catenas in the moist forest of Tai National Park, Ivory Coast. Journal of Tropical Ecology, 10(03), 385-398.

R Core Team (2013). R: A language and environment for statistical computing. $R$ Foundation for Statistical Computing, Vienna, Austria. Retrieved from http:// www.R-project.org/

Rousseau, T., \& Van Hecke, P. (1999) Measuring biodiversity. Acta Biothepretica, 47, 1-5.

Salvador-Van Eysenrode, D., Bogaert, J., Zak-Mnacek, V., \& Ceulemans, R. (2003). Sapling diversity in canopy gaps in an Ecuadorian rainforest. Forest Science, 49(6), 909-917.

Sanford, R. L., Braker, H. E., \& Hartshorn, G. S. (1986). Canopy openings in a primary Neotropical lowland forest. Journal of Tropical Ecology, 2(03), 277-282.

Schliemann, S. A., \& Bockheim, J. G. (2011). Methods for studying treefall gaps: a review. Forest Ecology and Management, 261(7), 1143-1151.

Svenning, J. C. (2000). Small Canopy Gaps Influence Plant Distributions in the Rain Forest Understory. Biotropica, 32(2), 252-261.

Unger, M., Homeier, J., \& Leuschner, C. (2012). Effects of soil chemistry on tropical forest biomass and productivity at different elevations in the equatorial Andes. Oecologia, 170(1), 263-274.

Van der Meer, P. J., \& Bongers, F. (1996). Formation and closure of canopy gaps in the rain forest at Nouragues, French Guiana. Vegetation, 126(2), 167-179.

Vilčko F. (2003). Grid 2 - Simulation. Institut für Waldinventur und Waldwachstum [software]. Göttingen: Uni. Göttingen.

Watt, A. S. (1947). Pattern and process in the plant community. Journal of Ecology, 35(1/2), 1-22. 
Wehenkel, C., Brazão-Protázio, J. M., Carrillo-Parra, A., Martínez-Guerrero, J. H., \& Crecente-Campo, F. (2015). Spatial Distribution Patterns in the Very Rare and Species-Rich Picea chihuahuana Tree Community (Mexico). PloS One, 10(10), e0140442

Wehenkel, C., Corral-Rivas, J. J., \& Gadow, K. V. (2014). Quantifying differences between ecosystems with particular reference to selection forests in Durango/Mexico. Forest Ecology and Management, 316, 117-124.

Wehenkel, C., Corral-Rivas, J. J., Hernández-Díaz, J. C., \& von Gadow, K. (2011). Estimating balanced structure areas in multi-species forests on the Sierra
Madre Occidental, Mexico. Annals of Forest Science, 68(2), 385-394.

Weiner, J., \& Solbrig, O. T. (1984). The meaning and measurement of size hierarchies in plant populations. Oecologia, 61(3), 334-336.

Welden, C. W., Hewett, S. W., Hubbell, S. P., \& Foster, R. B. (1991). Sapling survival, growth, and recruitment: relationship to canopy height in a Neotropical forest. Ecology, 72(1), 35-50.

Whitmore, T. C. (1989). Canopy gaps and the two major groups of forest trees. Ecology, 70, 536-538. 